\title{
0 \\ O L HARES \\ A contação de história e seus contributos para a interação e desenvolvimento linguístico da criança
}

Acreciana de Sousa Melo Universidade do Estado do Rio Grande do Norte - UERN acrecianamelo@yahoo.com.br

Adelaide Alves Dias Universidade do Estado do Rio Grande do Norte - UERN adelaidealves@uern.br

Maria Lúcia Pessoa Sampaio Universidade do Estado do Rio Grande do Norte - UERN luciapessoa@uern.br

Raimunda Queiroz Rêgo Universidade do Estado do Rio Grande do Norte - UERN mundinharego@yahoo.com.br

\section{RESUMO}

Contar, ouvir e recontar histórias serve a diversos propósitos, especialmente à formação intelectual, psicológica, linguística e cultural do ser humano. Este artigo versa sobre a contação de histórias, sobretudo, como uma estratégia favorável às interações e ao desenvolvimento linguístico da criança. Tem como objetivo compreender como a contação de histórias viabiliza interações e o desenvolvimento linguístico das crianças, evidenciando sua importância nas práticas escolares. A pesquisa foi realizada em quatro turmas de $1^{\circ}$ ano do ensino fundamental de uma escola pública da cidade de São Miguel-RN. Baseia-se nos pressupostos da pesquisa qualitativa e caracteriza-se como pesquisa de campo. Utilizou-se como instrumento entrevistas semi-estruturadas com as quatro professoras, bem como a observação não participante de quatro sessões de contações de histórias em forma de teatro, desenvolvidas nas referidas turmas pelo Programa Biblioteca Ambulante e Literatura nas Escolas - BALE Micaelense, um Programa de extensão da Universidade do Estado do Rio Grande do Norte que visa estimular o gosto e o prazer pela leitura. Os resultados indicam que a contação de histórias contribui de forma significativa para o processo de interação e desenvolvimento da competência linguística das crianças, além de despertar a imaginação criadora através da capacidade de ouvir, participar, recontar e se expressar. Conclui-se que esta arte configura-se, portanto, uma importante estratégia de mediação e estímulo frente ao processo formativo das crianças.

Palavras-chave: Contação de história; Interação; Desenvolvimento linguístico. 


\section{O}

Storytelling and its contributions to children's interaction and linguistic development

\section{ABSTRACT}

Telling, listening and retelling stories serve several purposes, especially the intellectual, psychological, linguistic and cultural formation of the human being. This article deals with storytelling, above all, as a strategy favorable to the interactions and the linguistic development of the child. It aims to understand how storytelling enables interactions and children's linguistic development, highlighting its importance in school practices. The research was carried out in four classes of 1 st year of elementary school I of a public school in the city of São Miguel/RN. It is based on the assumptions of qualitative research and is characterized as field research. Semi-structured interviews with the four teachers were used as an instrument, as well as the non-participant observation of four storytelling sessions in the form of theater, developed in the classes by the Walking Library and Literature in Schools Program - BALE Micaelense, an extension program at the State University of Rio Grande do Norte that aims to stimulate the taste and pleasure of reading. The results indicate that storytelling contributes significantly to the process of interaction and development of children's linguistic competence, in addition to arousing the imagination through the ability to listen, participate, retell and express. We conclude that this art is, therefore, an important strategy of mediation and stimulation in the face of the children's educational process. Keywords: Storytelling; Interaction; Linguistic development.

\section{Introdução}

A contação de histórias é uma arte inestimável. Sua tradição, passada de geração em geração, é registrada em diversos contextos, reunindo expressões, conhecimentos e significados que ficam gravados na memória através da oralidade. As histórias contadas, ouvidas e recontadas servem a muitos propósitos, contribuindo para a formação intelectual, psicológica, linguística e cultural do ser humano.

Entretanto, outros interesses modernos aliados principalmente às tecnologias vêm preenchendo muitos dos espaços formativos, substituindo o lugar que até então era ocupado pelas narrativas, cuja função está cada vez mais distanciada das novas gerações, fazendo com que a literatura oral não tenha atualmente a atenção merecida.

Diante disso, torna-se necessário mobilizar discussões e reflexões, enfatizando a importância da leitura literária e sua valorização, especialmente na instituição escolar, por ser um ambiente propício à disseminação dessa arte e de estímulo ao desenvolvimento das crianças.

Nessa perspectiva, a contação de histórias representa uma estratégia de mediação pedagógica significativa, pois é uma arte convidativa, capaz de envolver, encantar, motivar, ensinar, despertar o gosto e prazer pela leitura e ainda promover o desenvolvimento de diversas habilidades na criança, entre as quais destacam-se a capacidade de interagir e ampliar o domínio linguístico, competências essas que são consideradas fundamentais tanto ao processo de formação humana, como à produção 
do conhecimento na escola.

Compreende-se que a contação de história se efetiva no momento em que há interação entre o contador e o público, atendendo as competências comunicativas desses interlocutores. Dessa forma, o contador precisa levar em conta tanto a preparação e o estudo da história, quanto idade, conhecimento prévio e cultura letrada do seu expectador. Além disso, quem conta deve criar estratégias e oferecer espaços para a plateia se envolver, se encantar e recriar.

Em face do exposto, o objetivo deste estudo é compreender como a arte de contar histórias promove interações e o desenvolvimento da linguagem nas crianças. Para tanto, foi realizada uma pesquisa empírica, de abordagem qualitativa, junto a professoras e alunos de quatro turmas do $1^{\circ}$ ano do ensino fundamental, de uma escola pública municipal da cidade de São Miguel-RN.

\section{Contação de história e desenvolvimento infantil}

De acordo com Amarilha (2009), uma concretização mais específica acerca do conceito de infância enquanto faixa etária diferenciada, nasce somente em fins do século XVIII. Nesse contexto, surgiram na Europa os primeiros livros para crianças, sendo uma literatura de cunho didático, repleta de intenções morais e pedagógicas, que visavam atender à necessidade de educar essa nova geração e instruí-la nos princípios civilizatórios, conforme as visões de mundo daquela sociedade.

Assim, a literatura infantil, vista como um dos instrumentos a serviço da norma em vigor, serviu apenas à burguesia como um fator indispensável para a harmonia entre pais e filhos, manutenção de um estilo de vida familiar e também para ensinar lições de comportamento e moral. Em geral, por meio dela, transmitiam-se ensinamentos de mundo segundo a visão adulta, portanto em desacordo com os reais interesses da infância (ZILBERMAN, 2003).

No Brasil, foi em torno de 1900 que a literatura infantil começou a se manifestar e criar os primeiros textos dessa natureza, também apresentando características semelhantes às encontradas na Europa, contemplando valores morais, cívicos e religiosos considerados adequados e necessários para uma boa formação perante os paradigmas da sociedade em vigor. Conforme Amarilha (2009, p. 46):

A partir de critérios pedagógicos, os livros que compunham as bibliotecas dos adultos foram adaptados para as crianças. As fontes foram diversas: os contos populares, lendas e fábulas se constituíram no primeiro repertório de literatura para as crianças. [...] nela predominava o tom instrucional e pedagógico [...].

Dessa forma, segundo a autora, tal literatura contribuiu para diminuir o seu prestígio diante do universo das manifestações artísticas, pois, o fato de tornar o texto divertido e simples para memorizá-lo não o afirmava como produção literária, embora o resultado fosse aprazível. Nesse contexto, a significação do texto servia mais ao adulto, limitando-se a uma pura intenção pedagógica. Com isso, percebe-se que o 
nascimento e a expansão da literatura infantil decorreram de exigências próprias da época, associando-se com a pedagogia por transmitir normas e se relacionar com a formação moral.

Em contrapartida a essa perspectiva, os autores contemporâneos buscam priorizar o universo infantil, valorizando o lúdico e a qualidade literária em detrimento dos aspectos pedagógicos, considerando os anseios e interesses da criança, de modo a the possibilitar um deleite apropriado e respeitar a sua capacidade criativa e interpretativa. Além disso, procuram considerar uma dimensão estética que a aproxime da arte, transformando-se em um meio de acesso ao real, provocando na criança o conhecimento de histórias, a liberdade para experimentações e a sua expansão linguística.

No que se refere aos benefícios oriundos das histórias, Giordano (2013, p. 41), corroborando com Candido (2002), relata que:

[...] quando pensamos a arte de contar histórias a associamos à humanização dos humanos, já que o homem não nasce humanizado ele se humaniza, e com isso, queremos dizer que ela (a arte de narrar) se insere numa dimensão formativa, isto é, a dimensão que aborda o desenvolvimento harmonioso do ser humano em todos os seus aspectos: razão, emoção, corpo e espírito.

A ação de contar histórias, para a autora, ajuda a desenvolver competências psicoafetivas, colaborando com o processo de simbolização, abstração e habilidade criativa, portanto, considera importante proporcionar diferentes formas de acesso à literatura através da arte de narrar. A pesquisadora acrescenta, ainda, que por meio dos textos o indivíduo é capaz de internalizar a cultura e desenvolver estratégias para lidar com os conflitos presentes na história e na realidade a qual está inserido, possibilitando à criança ativar emoções através dos dilemas enfrentados pelos personagens da história.

De acordo com Zilberman (2003), a literatura infantil possibilita o desenvolvimento das habilidades intelectuais e "transforma-se num meio de acesso ao real, na medida em que facilita a ordenação de experiências existenciais, pelo conhecimento de histórias, e a expansão de seu domínio linguístico" (ZILBERMAN, 2003, p. 46).

Para Villardi (1999), a oportunidade de acesso a obras literárias, pode contribuir para o desenvolvimento do gosto pela leitura e para um melhor desempenho escolar do aluno em todas as áreas do conhecimento. Para tanto, faz-se necessário proporcionar o prazer da descoberta, de modo que a leitura seja vista não como o cumprimento de uma tarefa, mas como algo privilegiado que permite fantasiar, criar, refletir e se libertar.

Na visão de Sisto (2012, p. 32), "contar histórias hoje significa salvar o mundo imaginário”, pois a literatura abre espaço para o pensamento mágico, possibilitando o livre exercício da imaginação criadora, aspecto esse que está ficando cada vez mais comprometido em meio à desenfreada era da tecnologia e da informação.

Vale mencionar ainda o pensamento da autora Coelho (2006) ao destacar que 
a história além de ser um importante alimento da imaginação é fonte de satisfação para a criança. Para ela "a história aquieta, serena, prende a atenção, informa, socializa, educa [...] permite a auto-identificação, favorecendo a aceitação de situações desagradáveis, ajuda a resolver conflitos, acenando com a esperança" (COELHO, 2006, p. 12).

Diante do exposto, percebe-se a importância da contação de histórias para o processo de desenvolvimento, formação e repertório cultural de todo ser humano, ao contribuir para a construção de si, para a elaboração de modos de intervir e interagir no mundo, bem como para o desenvolvimento do gosto e prazer pela leitura, o que comprova a necessidade da literatura infantil no seio da sociedade.

\section{Contação de história, linguagem, interação e mediação}

Partindo do pensamento de Vygotsky e Bakhtin acerca do papel da linguagem, pode-se inferir que a criança se desenvolve por meio das interações sociais, ou seja, a partir de suas relações com o outro. Conforme Freitas (1994), ambos os autores percebem estar na linguagem a essência da constituição humana como ser sociocultural. Isso leva a compreender que o processo educativo deve se dar de forma dinâmica, numa relação dialógica entre os sujeitos.

Nesse sentido, a instituição de educação infantil, configura-se como um espaço privilegiado para facilitar práticas interativas e incentivar produções da linguagem, reconhecida como instrumento fundamental para a construção social, histórica e cultural da criança enquanto sujeito ativo e participativo. Para Jobim e Sousa (1994, p. 21), "é na linguagem, e por meio dela, que construímos a leitura da vida e da nossa própria história".

Vale mencionar que, de acordo com Vygotsky, há uma interconexão entre linguagem e pensamento, mas cabe observar que ambos não coincidem. Conforme Martins (2011), a função da linguagem é servir de meio de comunicação, enquanto que o intuito do pensamento é conhecer e regular o comportamento. Contudo, entre eles ocorre uma conexão no decorrer do desenvolvimento, na medida em que a comunicação passa a demandar o pensamento e ele a se manifestar por meio da linguagem, o que foi sistematicamente explicado por Vygotsky (2001).

Ainda segundo Martins (2011), a linguagem, embora confira à sua formação um cunho aparentemente natural, só se desenvolve sob a dependência da ação do outro. Nesse sentido, sua exigência supera a mera "capacidade para falar" (MARTINS, 2011 , p. 09). Isso implica dizer que, apesar da criança aprender a falar espontaneamente, ela só poderá reorganizar essa capacidade por meio de estímulos e procedimentos específicos de ensino, onde assimilará os elementos da linguagem e seu uso, tanto na coordenação do discurso quanto na própria organização do pensamento.

É nesse contexto que entra o papel da mediação, conceito abordado na teoria Vygotskyana, que na concepção de Gadamer (1988), refere-se a um rico processo de interação entre sujeitos, tendo a linguagem como ambiente. Para esse entendimento, 
basta lembrar que é com a mediação dos adultos que a criança passa a internalizar as representações do mundo e criar suas próprias compreensões.

Assim, o papel dos educadores é fundamental na fase infantil, porque enquanto facilitam as interações com o ambiente e entre as crianças e mediam a construção de conhecimentos possibilitando vivências significativas, contribuem para o desenvolvimento discursivo delas, fazendo-as vivenciar sua constituição como sujeitos atuantes.

De acordo com a Base Nacional Comum Curricular (BNCC), essa interação define o cotidiano da infância e traz consigo muitas aprendizagens e potencialidades para o desenvolvimento integral das crianças (BRASIL, 2017).

Acerca do desenvolvimento humano e da relevância das interações diante deste processo, destaca-se a citação abaixo:

Para Vygotsky, as crianças se socializam, pois elas não são sociais por natureza, produzem-se no meio social, são seres interativos. A seu ver o desenvolvimento é um processo que deve considerar os aspectos biológicos e estes se transformam em culturais. Portanto, a criança se constitui como um sujeito interativo e, neste processo, utiliza a fala como um instrumento para organizar o pensamento. A interação é, então, o modo como os seres humanos vão se desenvolvendo mediante aspectos culturais (COSTAS e FERREIRA, 2010, p. 209).

Destarte, por meio das experiências sociais a criança vai construindo conhecimentos e ampliando o domínio dos aspectos linguísticos, como também ajustando e internalizando a sua compreensão acerca dos conteúdos culturais, conforme o contexto vivido por ela. Assim sendo,

No momento em que a criança interage com seus pares, sendo mediada pela professora, demonstra sua competência discursiva, constrói seus conhecimentos, ressignifica as normas e os valores de sua cultura, desenvolve a sua capacidade simbólica e, sobretudo, a linguagem vai sendo garantida [...] (LEMOS; DIAS, 2018, p. 132).

Com isso, percebe-se que a interação, a mediação e a linguagem assumem papeis essenciais no processo de construção e desenvolvimento da criança.

Como destaca Vygotsky, o acesso da criança aos conteúdos sociais é mediado por outros sujeitos através do uso de dois elementos, a saber: os instrumentos simbólicos e os signos culturalmente construídos, sendo a linguagem o principal sistema de signos.

Considerando essa discussão, pressupõe-se que a contação de histórias, compreende uma atividade capaz de potencializar interações e promover esse desenvolvimento da linguagem. Segundo Zilberman (2003), a linguagem é o instrumento mediador entre a criança e o mundo e propicia por meio da leitura um alargamento do domínio linguístico.

Concordando com esse pensamento, é possível destacar que as histórias "além de possibilitar o acesso à riqueza de vocabulário [...] pode ampliar o movimento dialógico entre as crianças, por se constituir em um momento de trocas [...]" (LEMOS; 
DIAS, 2018, p. 132). Isso porque há interação comunicativa entre quem conta e quem escuta, pois o ouvinte também é capaz de ser ativo no momento da contação, tanto pelas interferências que faz durante a história, como por meio dos significados que vai atribuindo àquilo que ouve.

Neste sentido, a ação de contar e ouvir histórias favorece uma recíproca vibração entre narrador e ouvintes, a ponto de todos ficarem envolvidos pelos estímulos dos enredos. Assim, seja na leitura, seja na escuta de uma história, os sujeitos interagem e participam ativamente.

Desse modo, o contador, envolvido com a história, usa de mecanismos para entusiasmar o ouvinte, utilizando a sua voz, o seu corpo e as expressões faciais "para estabelecer uma conexão entre ele próprio, a história que conta e seu público" (SANTOS; SILVA, 2016, p. 34). Nessa interação o professor assume o papel de mediador a partir de ações que levam o ouvinte a reconhecer o sentido oferecido pelo autor ou a construir outros sentidos, de forma a explorar e valorizar o texto, vinculandoo aos eventos linguísticos, sociais e cognitivos (MARCUSCHI, 2008).

Essas interações linguísticas ocorridas com o adulto, por meio das histórias, oferecem à criança a oportunidade de desenvolver a competência narrativa, auxiliando-a a interpretar, compartilhar e compreender melhor os fatos do cotidiano.

Notoriamente, a prática de contar histórias contribui de maneira prazerosa no processo de mediação do conhecimento, permitindo que a criança dê asas à imaginação, ao mesmo tempo em que entra em contato com o mundo letrado.

Conforme Amarilha (2009), a literatura educa e colabora de forma lúdica "para o acesso à língua em articulações próprias da linguagem escrita" (AMARILHA, 2009, p. 49), visto que para a criança o ritmo das frases, a sonoridade e a organização das palavras são pontos de referência no acesso à escrita. Nesse sentido, a experiência com a literatura possibilita que a criança reflita sobre o mundo que a cerca, fazendoa perceber a diversidade de estilos linguísticos e culturais, principalmente no período em que vivencia o processo de alfabetização, por demonstrar grande curiosidade pelas palavras.

Logo, com criatividade e organização pedagógica o educador pode realizar um trabalho encantador a partir dos contos, observando sempre a faixa etária, os interesses e o ritmo do grupo. Através dessa estratégia envolvente é possível mobilizar as crianças e estimulá-las diante do ato de ouvir e recontar histórias. Sobre essa ação, é imprescindível atentar para o fato de que:

\footnotetext{
Além de ser um exercício de socialização, a criança estará desenvolvendo aptidões importantes, como se expressar perante um grupo de pessoas com desenvoltura e domínio de espaço. Ao mesmo tempo estará entrando em contato com seus afetos, pois ao dar forma e expressão aos sentimentos contidos no texto ela aprenderá a lidar com os seus, e tudo isto leva, consequentemente, a uma ampliação dos seus recursos internos e a um amadurecimento psicológico (BUSATTO, 2012, p. 40).
}

De acordo com essa afirmação, fica evidente que a narrativa, por meio do 
reconto, pode estimular a linguagem oral da criança e abrir espaço para o reconhecimento do seu sujeito criador, servindo ao desenvolvimento intelectual e psicológico. À medida que a criança é estimulada a produzir linguagens, expressando oralmente suas representações sobre a história, desenvolve também sua consciência crítica, pois o ato de revelar suas impressões possibilita-lhe emancipar o seu pensamento, refletir acerca das atitudes dos personagens e participar ativamente do momento da contação de história, vivenciando uma experiência significativa.

Tal perspectiva constrói uma relação transformadora da criança com o livro, servindo a uma educação que não oprime, mas que emancipa. Corroborando com esse pensamento, salienta-se a seguinte afirmação:

A literatura infantil, nessa medida, é levada a realizar sua função formadora, que não se confunde com a missão pedagógica. Com efeito ela dá conta de uma tarefa a que está voltada toda a cultura - a de "conhecimento do mundo e do ser", como sugere Antônio Cândido, o que representa um acesso à circunstância individual por intermédio da realidade criada pela fantasia do escritor. E vai mais além - propicia os elementos para uma emancipação pessoal, o que é a finalidade implícita do próprio saber (ZILBERMAN, 2003, p. 30).

Dessa forma, compreende-se a importância da contação de histórias e do envolvimento e participação ativa da criança, reconhecendo-a como sujeito criativo que fala, expressa e constrói conhecimentos coletivamente. Afinal, contar histórias contribui para o desenvolvimento da autonomia linguística da criança, garantindo-lhe melhor domínio dos mecanismos de comunicação, e para que se torne cada vez mais integrada na sociedade.

\section{A literatura infantil no contexto escolar}

Conforme discutido anteriormente, a literatura infantil é um caminho de múltiplas possibilidades para o desenvolvimento e a aprendizagem das crianças nos aspectos linguístico, emocional, intrapessoal (autorreflexão e formação da própria identidade) e interpessoal (interações sociais). Além disso, "[...] a criança, durante a experiência com a literatura infantil, passa a refletir sobre o mundo que a cerca; essa, sem dúvida, configura-se como uma de suas singularidades" (LEMOS; DIAS, 2018, p. 135).

Assim sendo, a leitura literária desperta o pensamento crítico da criança a partir da reflexão que ela faz acerca das ações dos personagens e da sua relação com as experiências vivenciadas em seu cotidiano, transformando o mundo real em faz-deconta, numa interação entre ficção e realidade. Nesse sentido, Abramovich (1997) destaca:

É ouvindo histórias que se pode sentir (também) emoções importantes, como a tristeza, a raiva, a irritação, o bem-estar, o medo, a alegria, o pavor, a insegurança, a tranquilidade, e tantas outras mais, e viver profundamente tudo o que as narrativas provocam em quem as ouve - com toda a amplitude, significância e verdade que cada uma delas fez (ou não) brotar... Pois é ouvir, sentir e enxergar com os olhos do imaginário! (ABRAMOVICH, 
1997, p. 17).

Ao identificar-se com a história, a criança expressa sentimentos como se estivesse vivendo na realidade o que está sendo narrado, manifestando emoções importantes que as narrativas provocam através do imaginário.

Nesta análise, o Referencial Curricular Nacional para a Educação Infantil (RCNEI) orienta que desde cedo as crianças devem ser motivadas a ouvirem histórias literárias e, para isso, o professor precisa criar as condições necessárias tendo em vista atrair a atenção das crianças, permitindo que elas apreciem o texto e as imagens durante a leitura do livro (BRASIL, 1998). Pois,

Ter acesso à boa literatura é dispor de uma informação cultural que alimenta a imaginação e desperta o prazer pela leitura. A intenção de fazer com que as crianças, desde cedo, apreciem o momento de sentar para ouvir histórias exige que o professor, como leitor, preocupe-se em lê-la com interesse, criando um ambiente agradável e convidativo à escuta atenta, mobilizando a expectativa das crianças, permitindo que elas olhem o texto e as ilustrações enquanto a história é lida (BRASIL, 1998, p. 143).

Nesta perspectiva, Tahan (1964) aponta os benefícios da contação de histórias para o desenvolvimento infantil, conquistas e aprendizagens que a criança pode alcançar ao ouvir com frequência a leitura de obras literárias, a saber:

a. Expansão da linguagem infantil - enriquecendo o vocabulário e facilitando a expressão e a articulação;

b. Estímulo à inteligência - desenvolvendo o poder criador do pensamento infantil;

c. Aquisição de conhecimentos - alargando os horizontes e ampliando as experiências da criança;

d. Socialização - identificando a criança com o grupo e ambiente, levandoa estabelecer associações, por analogia, entre o que ouve e o que conhece;

e. Revelação das diferenças individuais - facilitando à professora o conhecimento de características predominantes em seus alunos, evidenciadas através das reações provocadas pelas narrativas;

f. Formação de hábito e atitudes sociais e morais - através da imitação de bons exemplos e situações decorrentes das histórias, estimulando bons sentimentos na criança e incitando-a na vida moral;

g. Cultivo da sensibilidade e da imaginação - condição essencial ao desenvolvimento da criança;

h. Cultivo da memória e da atenção - ensinando a criança a agir e preparando-a para a vida;

i. Interesse pela leitura - familiarizando a criança com os livros e histórias, despertamos, para o futuro, esse interesse tão necessário (TAHAN, 1964, p. 21).

Diante dessas vantagens, é imprescindível que o professor oportunize aos alunos momentos de leituras prazerosas a partir da contação de histórias, uma vez que "[...] ouvir histórias pode estimular o desenhar, o musicar, o sair, o ficar, o pensar, o teatrar, o imaginar, o brincar, o ver o livro, o escrever, o querer ouvir de novo (a mesma história ou outra). Afinal, tudo pode nascer dum texto! [...]" (ABRAMOVICH, 1997, p. 23). Essas possibilidades que a leitura literária oferece, instiga a 
aprendizagem da criança de forma lúdica, preservando o prazer e a magia da literatura infantil. Compete ao professor criar um ambiente propício à leitura, viabilizando o contato com os livros, mediando a leitura do texto literário e colocando os alunos como participantes ativos.

Para isso, Graves e Graves (1995) propõe a denominada experiência de leitura por andaime, que envolve três etapas práticas: pré-leitura, leitura e pós-leitura, tendo como objetivo assegurar aos alunos uma experiência de leitura bem-sucedida, de modo que eles possam construir sentidos para o texto.

Tal experiência inicia com a pré-leitura, na qual os alunos são motivados pelo professor a participarem da leitura através de questionamentos acerca do que os alunos acham que vai ser tratado no texto e para ativar os seus conhecimentos prévios.

No momento de leitura, propriamente dita, o professor define a melhor forma para realizar a contação da história, podendo ser por meio da leitura do próprio livro ou utilizando outras estratégias criativas. No caso dos alunos já alfabetizados, pode propor que leiam o texto silenciosamente ou que façam a leitura oral.

No tempo da pós-leitura, o professor motiva os alunos a recontarem a história que ouviram, expressando-se por meio das diferentes linguagens, como: linguagem oral, desenhos, pinturas ou dramatização. Referindo-se ao reconto oral, este é considerado como uma rica experiência de desenvolvimento linguístico e imaginação criadora, pois, por meio desta vivência, a criança tem a oportunidade de expressar o seu entendimento e ainda inserir novos elementos à sua forma original de recontar, podendo inclusive dar outro final à história, a partir dos sentidos que atribui ao texto literário ouvido, explorando sua criatividade, inteligência, raciocínio e imaginação.

Dessa forma, percebe-se que a contação de histórias é um recurso pedagógico importante que pode contribuir consideravelmente para a formação humana e cidadã das crianças, uma vez que "[...] como objeto que provoca emoções, dá prazer e diverte e, acima de tudo, modifica a consciência de mundo de seu leitor" (COELHO, 2000, p. 46). Nesta perspectiva, o trabalho pedagógico com essa arte promove nos estudantes o despertar da sensibilidade, das emoções, do prazer pela leitura e ainda o pensamento crítico acerca da realidade, formando e educando as crianças e os jovens para a vida em sociedade.

\section{A atuação do programa BALE Micaelense na escola}

O Programa Biblioteca Ambulante e Literatura nas Escolas (BALE) é um Programa de extensão universitária vinculado ao Departamento de Educação da Universidade do Estado do Rio Grande do Norte (UERN), Campus Avançado de Pau dos Ferros (CAPF) e foi criado pelas professoras Maria Lúcia Pessoa Sampaio e Renata de Oliveira Mascarenhas, no ano de 2007. Tem como objetivos principais incentivar o gosto e o interesse pela leitura e contribuir para a formação de leitores a partir do desenvolvimento de atividades literárias nas escolas, atendendo a cidade de Pau dos Ferros e também aos municípios vizinhos. 
Na cidade de São Miguel-RN, o Programa BALE atua desde 2014 e passa a ser chamado, nesta localidade, por BALE Micaelense para caracterizar a sua marca na referida cidade, contando com uma equipe formada por 21 membros voluntários, tendo em sua composição professores da comunidade local e estudantes dos cursos de Pedagogia, Letras e Geografia da Universidade do Estado do Rio Grande do Norte (UERN) e da Faculdade Evolução Alto Oeste Potiguar (FACEP).

É importante ressaltar que o Programa realiza diversas atividades literárias, como: rodas de leitura, contação de histórias, encenação em forma de teatro e sarau poético, seguidas de recontos realizados pelas próprias crianças após cada ação. As ações são realizadas uma vez por semana em uma escola pública da rede municipal de ensino, como também em eventos escolares de outras instituições do município e cidades circunvizinhas, mediante convite.

Além disso, o Programa BALE Micaelense desenvolve atividades literárias em espaços não escolares como: praça pública, Centro de Atenção Psicossocial (CAPS), Centro de Convivência e Fortalecimento de Vínculo, Centro Recreativo e Esportivo Micaelense. Portanto, a atuação no Programa BALE possibilita uma vasta e rica experiência aos voluntários do Programa e aos diversos públicos atendidos.

\section{Produção dos dados: um caminho cheio de encantos}

Nessa seção é apresentada a pesquisa de campo propriamente dita, realizada em uma escola de ensino fundamental da rede pública municipal da cidade de São Miguel/RN, a qual, em parceria com o Programa BALE Micaelense, realiza atividades semanais envolvendo a contação e o reconto de histórias, nos turnos matutino e vespertino, com duração de 01 hora cada ação.

A referida escola tem em funcionamento turmas do $1^{\circ}$ ao $5^{\circ}$ ano. Entretanto, para a constituição do corpus desta pesquisa foram selecionadas apenas as quatro turmas de $1^{\circ}$ Ano, considerando os seguintes critérios: I) Ser a primeira série da etapa do ensino fundamental; II) Ser a primeira série do ciclo de alfabetização.

Os sujeitos da pesquisa foram as quatro professoras do $1^{\circ}$ ano e seus respectivos alunos. As professoras são todas efetivas (concursadas), com idades variando de 35 a 45 anos, licenciadas em Pedagogia e participantes do Programa BALE. Os alunos totalizaram 117 estudantes nas quatro turmas, sendo 54 meninos e 63 meninas, com idades de 06 e 07 anos.

Para manter o sigilo e preservar a identidade dos sujeitos, atendendo aos princípios éticos da pesquisa, optou-se pela não identificação dos seus nomes próprios. No caso das professoras, foram utilizadas as iniciais dos seus nomes. Para os estudantes foi apenas informada a sua condição de aluno.

Ainda com relação aos cuidados éticos na condução do estudo, é válido ressaltar que as ações para a produção dos dados foram organizadas após a assinatura do termo de consentimento livre e esclarecido por parte das professoras e dos responsáveis pelas crianças, de modo a não causar nenhum custo e nenhum 
constrangimento a eles. O processo ocorreu de forma tranquila e segura.

Para a produção dos dados, foram realizadas entrevistas semi-estruturadas com as quatro professoras, com o objetivo de conhecer suas concepções acerca dos contributos das contações de histórias para o desenvolvimento das crianças, sobretudo, nos aspectos referentes às interações e desenvolvimento linguístico. Além da entrevista, foi realizada observação não participante, mediante a qual presenciouse os fatos, mas sem participar deles, assumindo apenas o papel de espectador (PRODANOV e FREITAS, 2013), com a finalidade de se perceber na prática como se dá o envolvimento e a participação das crianças e quais situações são criadas e promovidas para provocar esta atuação.

As observações aconteceram em quatro seções de contação e reconto de histórias, uma por turma, promovidas pelos voluntários do Programa BALE, no dia 09 de outubro de 2019 , sendo duas observações no período matutino e duas no turno vespertino.

De posse dos dados, foi feita uma análise interpretativa, relacionando os resultados das observações realizadas e as falas das professoras com o referencial teórico utilizado, com o propósito de se compreender de que maneira as contações de histórias promovem a interação e o desenvolvimento linguístico das crianças, conforme será descrita nas seções seguintes.

\section{Observações da ação do Programa BALE Micaelense}

Nas sessões de contação e reconto de histórias foram apresentadas as histórias intituladas "O grande rabanete" da autora Tatiana Belinky e "Menina bonita do laço de Fita" escrita por Ana Maria Machado, as quais foram interpretadas de forma teatral pelos voluntários do Programa BALE Micaelense, caracterizados com figurinos dos personagens da história.

Para as duas turmas do turno matutino, foram contadas a história "Menina bonita do laço de Fita". Ambas ocorreram dentro da própria sala de aula, na presença das professoras titulares de cada uma das turmas. Inicialmente, os voluntários do Programa BALE informaram ao público o título do livro e o nome da autora e, em seguida, iniciaram a apresentação da história.

No decorrer da contação, através da encenação da história, foi possível perceber os olhares de encantamento das crianças numa escuta atenta da narrativa. A expressão de alegria estampada nos seus rostos e as risadas espontâneas revelaram a sensibilidade e o envolvimento delas com os personagens da história e com o contexto da ficção.

Após a dramatização, os membros do Programa BALE mediaram o reconto da história, convidando as crianças para participarem. Foi um momento de muito envolvimento e interação entre as crianças. O reconto foi realizado de forma oral e coletiva, contando com a colaboração espontânea da maioria dos alunos, numa relação de respeito mútuo, de modo que cada um aguardava a sua vez de participar recontando e dando continuidade à história, expressando suas opiniões, a 
compreensão do texto e os sentimentos que despertaram neles ao ouvirem/assistirem a contação/encenação.

Essas manifestações das crianças, nas situações envolvendo a contação e o reconto de histórias, vão ao encontro do pensamento de Sisto (2012), que ressalta o poder da experiência com as histórias narradas a partir das sensações, da imaginação criadora dos ouvintes e da beleza dada em palavras pelo bom narrador, que conta "a história pelo prazer de dizer" (SISTO, 2012, p. 24).

Em relação ao turno vespertino, as duas turmas foram conduzidas ao galpão da escola, onde assistiram à contação/encenação da história "O grande rabanete". Assim como nas turmas anteriores, os mediadores do Programa BALE iniciaram a narração da história literária informando o nome do livro e da autora.

Esse momento gerou muita animação, pois a encenação foi acompanhada pelo toque de instrumentos musicais (pandeiros) e por uma música cantada, favorecendo assim a participação ativa dos contadores/voluntários do Programa BALE e das crianças.

Entre os aspectos observados nesta sessão literária, destacaram-se a atenção, a empolgação e a interação das crianças no momento da contação da história. Conforme apareciam novos personagens na encenação, as crianças expressavam contentamento, criando expectativas em relação à história. Foi possível perceber também o despertar das emoções e da sensibilidade, além da motivação para coparticipação de todos na narrativa, estimulando a interação e a imaginação através da relação entre ficção e realidade.

Após a encenação da história, os mediadores do Programa BALE convidaram as crianças para fazerem o reconto oral da história, relatando também, as impressões e os sentimentos que tiveram acerca do texto. Algumas crianças se disponibilizaram a participar e recontaram a história de forma espontânea, apresentando sequência lógica dos acontecimentos e utilizando expressões simples do seu próprio vocabulário, ou seja, palavras que elas já dominam e fazem parte do seu contexto social e cultural.

A seguir, apresenta-se a demonstração de um reconto da história "Menina bonita do laço de fita", produzido por uma das alunas do $1^{\circ}$ Ano que assistiu a história atentamente:

Quadro 1 - Reconto da história "Menina bonita do laço de fita" (Ana Maria Machado)

Era uma vez uma menina bonita do laço de fita. O coelho foi lá na casa dela e viu a menina. O coelho disse: menina bonita do laço de fita, qual é teu segredo para ser tão pretinha? A menina não sabia e inventou: deve ser porque eu comi muita jabuticaba quando era pequenininha. $\mathrm{O}$ coelho foi e comeu as jabuticabas. Ficou com a pança tão, tão grandinha, aí gritou: agora eu quero fazer cocô [risos] ele foi e ficou com o cocô do jeito de jabuticaba e não ficou preto. Aí ele voltou na casa da menina e disse: menina bonita do laço de fita, qual é teu segredo para ser tão pretinha? A menina não sabia e inventou: deve ser porque eu tomei muito café quando era pequenina. Aí o coelho foi e disse: agora eu vou tomar café. Foi e tomou muito café. Não conseguiu dormir, passou a noite inteira fazendo xixi [risos]. Aí depois ele voltou à casa da menina. A mãe da menina estava com ela. Ela estava na sala com um pote de feijoada. Aí [pausa], aí o coelho disse: menina bonita do laço de fita, qual é teu segredo para ser tão pretinha? Ela já sabia e sua mãe disse: foi porque eu tive uma mãe negra, e então, eu tive minha filha e foi negra. $E$ foi e eles viveram felizes para sempre [palmas]. 
Fonte: elaborada pelas autoras.

Conforme Coelho (2006, p. 57, grifo nosso), "a criança por si só percebe a mensagem contida na história e a revela nas colocações que faz", evidenciando o resultado da narrativa ouvida e a sua repercussão.

Nesse contexto, percebe-se a importância do reconto oral como estratégia estimuladora do desenvolvimento linguístico da criança, pois, por meio desta prática, ela explora sua oralidade, podendo ampliar e enriquecer o seu vocabulário, ao criar várias formas de se comunicar e se expressar, recriando a sua história. Além disso, a arte de recontar histórias possibilita o despertar da criatividade, a participação ativa das crianças nas experiências vividas com textos literários e a ampliação do repertório de leitura.

\section{Concepções das professoras acerca da importância da contação de histórias}

De acordo com Busatto (2006, p. 10) "contar histórias é uma arte porque traz significações ao propor um diálogo entre as diferentes dimensões do ser". Neste sentido, a contação de histórias contribui para a formação da criança em vários aspectos, como: intelectual, social e emocional, estimulando a criatividade, a imaginação, a fantasia, as interações, o desenvolvimento linguístico, a criticidade e o enriquecimento cultural.

As professoras colaboradoras da pesquisa enfatizaram a importância da contação de histórias para o desenvolvimento da criança nos aspectos já mencionados, acrescentando a sua relevância no estímulo à curiosidade, oralidade e ao gosto pela leitura, destacando-se as falas a seguir:

Quadro 2 - Importância da contação de histórias na perspectiva das professoras

\begin{tabular}{|c|l|}
\hline SUJEITOS & \multicolumn{1}{c|}{ RESPOSTAS DAS PROFESSORAS } \\
\hline P1 (M.E.C) & $\begin{array}{l}\text { Possibilita a autonomia, imaginação, criatividade, oralidade, a produção, } \\
\text { levando-os a interagir no meio do convívio [...]. }\end{array}$ \\
\hline P2 (M.A.N) & $\begin{array}{l}\text { A contação de história desperta a atenção da criança, conduzindo-a a interagir } \\
\text { com o contexto da história através da imaginação. }\end{array}$ \\
\hline P3 (M.E.N.B) & $\begin{array}{l}\text { A contação de história instiga a imaginação, a criatividade, a oralidade, como } \\
\text { também, incentiva o gosto pela leitura [...]. }\end{array}$ \\
\hline P4 (M.E.F.P) & $\begin{array}{l}\text { [...] Explora os sentidos, aguça a imaginação, a curiosidade, a criatividade. Sem } \\
\text { falar que elas entram em contato com a literatura. É um caminho que leva a } \\
\text { criança a desenvolver a imaginação, emoções e sentimentos de forma prazerosa } \\
\text { e significativa. É importante para a formação de qualquer criança ouvir muitas, } \\
\text { pois é através dos livros e contos infantis que a criança enfoca a importância de } \\
\text { ouvir, contar e recontar. }\end{array}$ \\
\hline
\end{tabular}

Fonte: elaborada pelas autoras.

Como se pode observar, na concepção das educadoras, a contação de histórias é uma prática que promove, em especial, o desenvolvimento da imaginação e da criatividade, o que vai ao encontro do pensamento de Busatto (2006, p. 58-59) quando afirma que "contar histórias pode ser fermento para o imaginário. Elas nascem 
no coração e [...] se espalham por todos os sentidos, devaneando, gatiando, até chegar ao imaginário [...]". Nessa perspectiva, as experiências com as contações de histórias favorecerem a capacidade de fantasiar, transpondo o tempo e o espaço vivido, na medida em que pode se imaginar em outros mundos e situações.

Nas falas, observou-se também a relevância da prática de contar histórias para a aprendizagem e desenvolvimento das crianças nos aspectos linguístico, cognitivo e de intercâmbio entre ficção e realidade, por meio da imaginação.

Quadro 3 - Relevância da contação de história para aprendizagem e desenvolvimento das crianças

\begin{tabular}{|c|l|}
\hline SUJEITOS & \multicolumn{1}{c|}{ RESPOSTAS DAS PROFESSORAS } \\
\hline P1 (M.E.C) & $\begin{array}{l}\text { A contação de história é fundamental no processo de aprendizagem das crianças. } \\
{[\ldots] \text { A literatura aguça a mente e propicia o envolvimento social e afetivo. }}\end{array}$ \\
\hline P2 (M.A.N) & $\begin{array}{l}\text { [...] Constitui um momento significativo de interação entre o mundo real e o } \\
\text { imaginário da Literatura Infantil. }\end{array}$ \\
\hline P3 (M.E.N.B) & $\begin{array}{l}\text { É um instrumento muito valioso no estímulo à leitura, ao desenvolvimento da } \\
\text { linguagem, é um caminho que leva a criança ao mundo da imaginação. }\end{array}$ \\
\hline P4 (M.E.F.P) & $\begin{array}{l}\text { [...] Desperta nas crianças o prazer de ler as histórias que os livros trazem e fazê- } \\
\text { las viajar em sua imaginação, criar e recriar suas histórias e aprimorar seus } \\
\text { conhecimentos, melhorando assim sua aprendizagem. }\end{array}$ \\
\hline
\end{tabular}

Fonte: elaborada pelas autoras.

É possível notar que os discursos das professoras legitimam o pensamento de Coelho (2006, p. 26) quando afirma que "a criança que ouve histórias com frequência educa sua atenção, desenvolve a linguagem oral e escrita, amplia seu vocabulário e principalmente aprende a procurar nos livros novas histórias para o seu entretenimento". Desse modo, evidencia-se que a contação de histórias representa um valioso instrumento no processo educativo.

Desta forma, o contato com essa arte torna-se fundamental principalmente para as crianças que estão na fase de desenvolvimento da linguagem oral e escrita, configurando-se um exercício que colabora para estimular o interesse, o raciocínio e a atenção, tão pertinentes ao processo de alfabetização.

A literatura também contribui para a formação humana, pois através dela a criança pode conhecer o mundo e estabelecer vínculos afetivos com o professor/contador e com seus pares, através das interações. Nessa perspectiva, Busatto (2006, p. 13) argumenta que a prática de contar histórias é "[...] um ato social e coletivo, que se materializa por meio de uma escuta afetiva e efetiva", despertando na criança emoções e sensibilidade, além de auxiliar na formação da identidade e na compreensão da realidade.

Ainda na concepção das professoras, contar histórias contribui também para a formação humana e cidadã, mediante o envolvimento social e afetivo, possibilitando a compreensão de fatos e problemas através dos conflitos e emoções vividos pela ficção, conforme observa-se nas falas a seguir:

Quadro 4 - Contação de história e formação humana e cidadã

\begin{tabular}{|c|l|}
\hline SUJEITOS & \multicolumn{1}{c|}{ RESPOSTAS DAS PROFESSORAS } \\
\hline P1 (M.E.C) & $\begin{array}{l}\text { [...] A literatura é uma prática, uma intervenção necessária para a formação } \\
\text { cidadã e atuação no meio social [...]. }\end{array}$ \\
\hline
\end{tabular}




\begin{tabular}{|c|l|}
\hline P2 (M.A.N) & $\begin{array}{l}\text { Na compreensão de fatos e problemas vivenciados pelas crianças [...]. Elas se } \\
\text { tornam coparticipantes dos conflitos e emoções vividos pelos personagens. }\end{array}$ \\
\hline P3 (M.E.N.B) & $\begin{array}{l}\text { [...] A contação de história contribui na formação da personalidade da criança } \\
\text { envolvendo o social e o afetivo. }\end{array}$ \\
\hline P4 (M.E.F.P) & $\begin{array}{l}\text { [...] A leitura tem a devida importância e utilização, pois a mesma é um importante } \\
\text { instrumento de formação humana, repassando assim, aos meus alunos o prazer } \\
\text { em ler um livro, uma revista, um jornal e também em ser questionador, em } \\
\text { transformar a realidade e ainda ter a possibilidade de viajar por outras culturas, } \\
\text { outros valores. }\end{array}$ \\
\hline
\end{tabular}

Fonte: elaborada pelas autoras

Neste sentido, Abramovich (1997, p. 16) reforça que "[...] é importante para a formação de qualquer criança ouvir muitas, muitas histórias [...]. Escutá-las é o início da aprendizagem para ser um leitor, e [...] ter um caminho absolutamente infinito de descoberta e de compreensão do mundo [...]". Logo, reafirma que esta é uma prática imprescindível para o desenvolvimento da criança, desde a mais tenra idade, pois quanto mais cedo imergir no mundo da leitura, maiores serão as possibilidades de se constituir leitor, ampliar o vocabulário, conhecer outras culturas e aprender novos conhecimentos.

Por meio da contação de histórias, viabiliza-se a percepção da própria identidade das crianças, ao permitir identificarem-se com os personagens, estabelecendo relações com vivências do cotidiano e a compreensão de conflitos, fatos e problemas sociais da realidade.

Por fim, percebe-se que as professoras/colaboradoras da pesquisa reconhecem a contribuição da prática de contar histórias na sala de aula, haja vista a sua influência na aprendizagem e no desenvolvimento dos alunos, auxiliando na formação de sujeitos leitores para a vida e possibilitando-lhes uma experiência lúdica e criativa, bem como o despertar de diversos aspectos, conforme mencionados nessa discussão.

\section{Conclusão}

A fim de se compreender como a contação de histórias viabiliza interações e o desenvolvimento linguístico das crianças, de modo a evidenciar suas contribuições nas práticas escolares, foram observadas e analisadas quatro seções de contações de histórias promovidas pelo Programa BALE Micaelense em uma escola pública municipal, bem como uma análise acerca das falas das professoras sobre a importância dessa atividade para o desenvolvimento das crianças.

Com base nas análises realizadas, conclui-se que a contação de histórias ocupa lugar privilegiado nas atividades desenvolvidas nas instituições escolares, sendo uma significativa estratégia de mediação e uma verdadeira fonte de estímulos ao crescimento cultural e ao processo formativo do ser humano, além de ser favorável a construção de vínculos afetivos e sociais, os quais ocorrem naturalmente entre ouvintes e narradores.

Os resultados indicam que a contação de histórias contribui significativamente para o processo de interação e desenvolvimento da competência linguística das 
crianças, através da capacidade de ouvir, participar, recontar e se expressar, sendo, portanto, um instrumento enriquecedor das práticas educativas, pois funciona como agente gerador de inspiração, imaginação criadora, criatividade e expressão.

Tendo em vista os resultados encontrados, criar oportunidades para que o lúdico aconteça por meio da contação de histórias viabiliza espaços potentes para mobilizar reflexões, contribuir para a disseminação de conhecimentos e colaborar para a valorização de práticas educativas sistemáticas envolvendo as contações de histórias nas escolas.

\section{Referências}

ABRAMOVICH, F. Literatura infantil: gostosuras e bobices. 5. ed. São Paulo: Scipione, 1997.

AMARILHA, M. Estão mortas as fadas? 8. ed. Petrópolis: Vozes, 2009. BRASIL. Ministério da Educação e do Desporto. Secretaria de Educação Fundamental. Referencial Curricular Nacional para a Educação Infantil. vol. 3. Brasília, DF, 1998.

BRASIL. Ministério da Educação. Governo Federal. Secretaria da Educação Básica. Base Nacional Comum Curricular: educação é a base. Brasília, DF, 2017. BUSATTO, C. A arte de contar histórias no século XXI: tradição e ciberespaço. Petrópolis: Vozes, 2006.

BUSATTO, C. Contar e encantar: pequenos segredos da narrativa. 8. ed. Petrópolis: Vozes, 2012.

CANDIDO, A. A literatura e a formação do homem. In: DANTAS, V. Textos de intervenção. São Paulo: Duas Cidades, 2002.

COELHO, N.N. Literatura infantil: teoria, análise, didática. São Paulo: Moderna, 2000.

COELHO, B. Contar histórias: uma arte sem idade. 10. ed. São Paulo: Ática, 2006. COSTAS, F.A.T.; FERREIRA, L.S. Sentido, significado e mediação em Vygotsky: Implicações para a constituição do processo de leitura. Revista lberoamericana de Educación. №55, p. 205-223, 2010. Disponível em:

https://rieoei.org/historico/documentos/rie55a09.pdf. Acesso em: 18 de abril de 2020. FREITAS, M.T.A. Vygotsky e Bakhtin. Psicologia e Educação: um intertexto. São Paulo: Ática, 1994.

GADAMER, H-G. Verdad y método. Fundamentos de una hermenêutica filosófica.

3. ed. Salamanca: Ediciones Sígueme, 1988.

GIORDANO, A. A arte de contar histórias e o conto de tradição oral em práticas educativas. Construção psicopedagógica. São Paulo, v. 21, n. 22, p. 26-45, 2013. Disponível em: http://pepsic.bvsalud.org/scielo.php?script=sci_arttext\&pid=S141569542013000100004. Acesso em: 10 de maio de 2020.

GRAVES, M.F.; GRAVES, B.B. A experiência de leitura com andaimes: uma referência flexível para ajudar os estudantes a obter o máximo do texto, 1995. 
JOBIM e SOUZA, S. Infância e linguagem: Bakhtin, Vygotsky e Benjamin.

Campinas, SP: Papirus, 1994.

LEMOS, S.A.N.; DIAS, A.A. Infância e linguagem: a importância da literatura infantil no processo de desenvolvimento da criança pequena. In: DIAS, A. A.; AMORIM, A. L. N. (Orgs.). As crianças, suas infâncias e educação: itinerâncias de 15 anos do Núcleo de Pesquisas e Estudos sobre Criança (Nupec). Curitiba: Appris, 2018, p. $131-144$.

MARCUSCHI, L. A. Produção textual, análise de gêneros e compreensão. São Paulo: Parábola Editorial, 2008.

MARTINS, L. O desenvolvimento do psiquismo e a educação escolar: contribuições à luz da psicologia histórico cultural e da pedagogia histórico-crítica. Tese de livre docência. Bauru, 2011. Disponível em:

https://www.scielo.br/scielo.php?script=sci_arttext\&pid=S1414-32832012000100025. Acesso em: 22 de maio 2020.

PRODANOV, C.C.; FREITAS, E. C. Metodologia do trabalho científico: métodos e técnicas da pesquisa e do trabalho acadêmico. 2. ed. - Novo Hamburgo, RS:

Feevale, 2013.

SANTOS, F.C.; SILVA, L.U.M. A linguística no processo do contar histórias: uma contribuição para a neuroeducação. In: SANTOS, F.; CAMPOS, A.M. (Orgs.). A contação de histórias: contribuição à neuroeducação. Rio de Janeiro: Wak Editora, 2016, p. 21-39.

SISTO, C. Textos \& pretextos sobre a arte de contar histórias. 3. ed. - Belo Horizonte: Aletria, 2012.

TAHAN, M. A arte de ler e contar histórias. 4. ed. Rio de Janeiro: Conquista, 1964. VILLARDI, R. Ensinando a gostar de ler e formando leitores para a vida inteira. Rio de Janeiro: Qualitymark/Dunya, 1999.

VYGOTSKY, L.S. Obras Escogidas. Tomo II. Madrid: Visor, 2001.

ZILBERMAN, R. A literatura infantil na escola. 11. ed. - São Paulo: Global, 2003.

Recebido em: (14/09/2020)

Aceito em: (06/11/2020) 